\title{
Photoreactivation of Ultraviolet Induced Reciprocal Recombination, Gene Conversion and Mutation to Prototrophy in Saccharomyces cerevisiae
}

\author{
By JAMES M. PARRY AND B. S. COX \\ Department of Genetics, The University of Liverpool, Liverpool, 3
}

(Received 24 February 1965)

\begin{abstract}
SUMMARY
Strains of Saccharomyces cerevisiae heteroallelic for the adenine-2 locus, heterozygous for outside markers and homozygous for tryptophan-1, were ultraviolet (u.v.)-irradiated and the effect of post-treatment with white light determined. Mitotic gene conversion to adenine independence and mutation to tryptophan independence and to adenine independence were both decreased by post-u.v.-irradiation treatment with white light, whereas mitotic reciprocal recombination of outside markers was unaffected. The effect of varying the treatment with white light after a constant degree of exposure to u.v.-radiation produced a decrease in reversion frequency to a constant value at light exposures of $5 \mathrm{~min}$. and more. The differing responses of reciprocal recombination and gene conversion are discussed.
\end{abstract}

\section{INTRODUCTION}

The effect of post-treatment with white light of ultraviolet (u.v.)-irradiated cells has been studied in bacteria (Doudney \& Haas, 1958). Post-treatment has been shown to produce a decrease in the number of prototrophic revertants amongst the survivors of u.v.-irradiation. Changes of genotype during mitosis in diploid yeast may be due to one of three events: mutation, reciprocal recombination and gene conversion or non-reciprocal recombination (Roman, 1956a,b). Gene conversion in yeast was reviewed by Roman (1963) and Holliday (1964). Both gene conversion and reciprocal recombination, detected by the formation of homozygous recessive colonies in a heterozygous diploid, have been demonstrated to increase with u.v.irradiation (James \& Lee-Whiting, 1955; Roman, 1958), and it has been shown that a correlation exists between the occurrence of gene conversion and reciprocal recombination (Fogel \& Hurst, 1963; Kakar, 1963). Roman \& Jacob (1958) showed, however, that the proportion of reciprocal recombinants recovered among cells in which gene conversion had occurred decreased with increasing dosage of u.v. radiation.

Diploid Saccharomyces cerevisiae which is heteroallelic at the adenine-2 locus, $2 \mathrm{n}=a d_{2, \mathrm{1}} / a d_{2, \mathrm{c}}$ is red and requires adenine for growth. The symbols used here and throughout the text are those agreed to at the Carbondale Yeast Genetics Conference, 1963. The subscripts in $a d_{2,1}$ and $a d_{2, c}$ indicate that the mutations are independently isolated recombining alleles of the $a d_{2}$ locus. Gene conversion may occur during mitosis to give heterozygous diploids of either $a d_{2,1} /+$ or $a d_{2, c} /+$ genotype, with a corresponding change in phenotype from red adenine-requiring to white prototrophic. The double mutant heterozygote, $2 n=a d_{2,1}-a d_{2,} d+$ has not been 
found (Cox, 1963). The present paper reports an investigation of the effect of white light as a post-treatment to u.v.-irradiation on gene conversion in such a heteroallelic diploid, on reciprocal recombination at outside markers from a heterozygous to a homozygous recessive condition and on mutation to prototrophy.

\section{METHODS}

Strains. The Saccharomyces cerevisiae diploids used were composed as follows:

$$
\begin{aligned}
98 / 2 d \times 111 / 1 d & =a / \alpha, a d_{2,1} \mid a d_{2,}, h i_{\mathrm{g}} /+, s e /+, \\
J 20-10 \times 126 W 5 a & =a\left|\alpha, a d_{2,1}\right| a d_{2,}, h i_{8}|+,+| m e_{2},+\mid s e_{1}, \operatorname{tr}_{1} / \operatorname{tr}_{1} .
\end{aligned}
$$

The haploids used were:

$$
\begin{aligned}
W 71 / 1 a & =\alpha, a d_{2, \mathrm{c}} s e_{1}, t r_{1} ; \\
J 20-10 & =\alpha, a d_{2, \mathrm{c}} m e_{2}, s e_{1}, t r_{1} ; \\
126 W 5 a & =a, a d_{2,1}, h i_{\mathrm{s}}, t r_{1} .
\end{aligned}
$$

All strains are derived from cultures originally provided by $\mathrm{Dr}$ D. C. Hawthorne. The markers $a d_{2}, s e_{1}$, and $h i_{8}$ are linked on chromosome XII as follows:

centromere-30-hi $i_{8}-15-s e_{1}-23-a d_{2}$ (Carbondale Yeast Genetics Conference, 1963).

Media. The complete medium used was described by Cox \& Bevan (1962). It is a yeast-extract + peptone medium with $4 \%(\mathrm{w} / \mathrm{v})$ glucose added; $\mathrm{pH} 6 \cdot 7$. The minimal medium was Difco Yeast Nitrogen Base without amino acids, solidified with Oxoid Ionagar, supplemented with growth factors as necessary and adjusted to pH 6.7.

Treatment. Before u.v.-irradiation, strains were grown for 2 days on complete medium agar, and suspended in saline at a titre of $10^{7}$ organisms $/ \mathrm{ml}$. Samples (10 ml.) of this suspension were u.v.-irradiated in a Petri dish at $25 \mathrm{~cm}$. from a Hanovia Model 11 a ultraviolet lamp, generating almost entirely monochromatic radiation at $2537 \AA$. All manipulations were done in red light to avoid photoreactivation. For exposure to white light, $5 \mathrm{ml}$. samples were taken from the treated suspension and put into a boiling tube. The boiling tube was immersed in a cooled water-jacket with $5 \%(w / v) \mathrm{CuSO}_{4}$ as a heat filter. The white light source was two $200 \mathrm{~W}$. Phillips Photoflood lamps set at right angles to each other. The following treatments were applied.

(1) Diploid J 20-10 $\times 126 W 5 a$. Ultraviolet treatment for 0-90 sec., with and without post-treatment with white light for $5 \mathrm{~min}$. The treated samples were scored for reversion to adenine independence, tryptophan independence, homozygosis at other loci and survival.

(2) Diploid $98 / 2 d \times 111 / 1 d$. U.v.-treatment for 60 sec.; post-treatment with white light from 0 to $40 \mathrm{~min}$. The treated samples were scored for reversion to adenine independence and survival.

(3) Haploid W71/1a. U.v.-treatment for 60 sec.; post-treatment with white light from 0 to $40 \mathrm{~min}$. The treated samples were scored for reversion to adenine independence and survival.

(4) Haploids J 10-10 and 126W5a. U.v.-treatment for 0-90 sec. The treated samples were scored for reversion to adenine independence and survival.

Method of testing for reversions and homozygosis. Reversions to adenine independence or tryptophan independence were detected by plating treated samples on minimal medium agar supplemented with amino acids but without adenine or 
tryptophan. No attempt was made to distinguish between reversion and suppression due to mutations at other loci. Homozygosis was detected by replicating the colonies formed on complete medium agar by treated samples on suitably supplemented minimal medium agar.

\section{RESULTS}

The data on the survival and reversion to adenine independence in strain $J 20-10$ $\times 126 W 5 a$ is expressed in Figs. 1 and 2. Fig. 1 shows that the effect of post-treatment with white light was to increase the $\%$ survival. Fig. 2 shows that the effect of post-treatment with white light was to decrease the $\%$ of revertant colonies amongst the survivors of u.v.-irradiation. These results indicate that the effect of white light post-treatment was to diminish the effect of u.v.-irradiation, whether measured as survival (about a ten-fold increase in the survival at u.v.-irradiation for $90 \mathrm{sec}$.) or as the frequency of revertant colonies (a decrease from about $0 \cdot 2$ to $0 \cdot 1$ revertants $\%$ survivors at 60 sec. u.v.-irradiation).

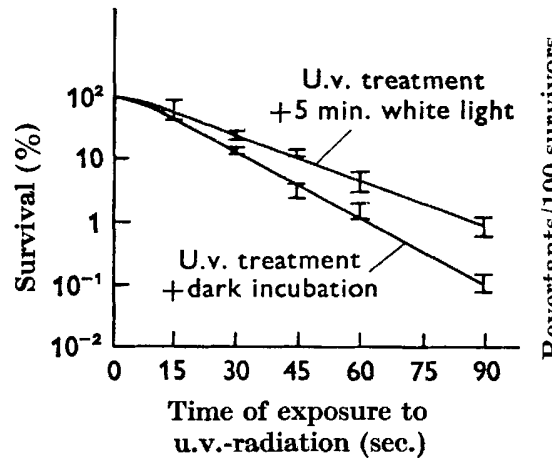

Fig. 1

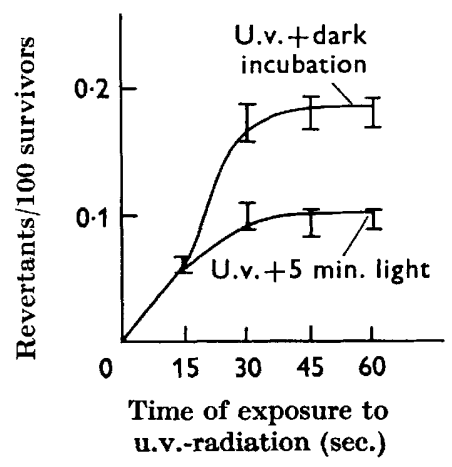

Fig. 2

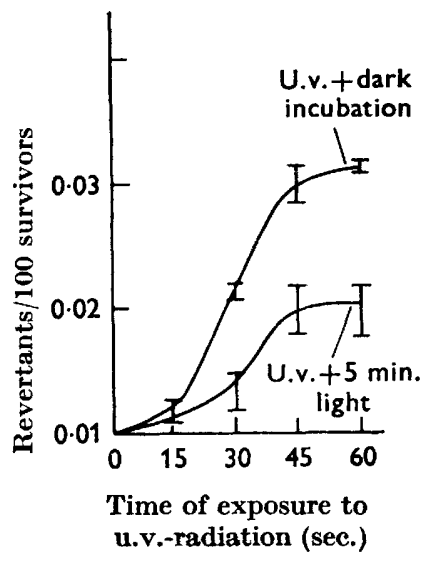

Fig. 3

Fig. 1. Survival values at various exposures to u.v.-radiation with and without 5 min. post-treatment with white light in Saccharomyces cerevisiae diploid $J 20-10 \times 126 \mathrm{~W} 5 a$. The vertical bars show the $95 \%$ probability limits.

Fig. 2. Reversion frequency expressed as \% reversions to adenine independence/survivor at various exposures to u.v.-radiation, with and without $5 \mathrm{~min}$. post-treatment with white light; Saccharomyces cerevisiae diploid strain $J 20-10 \times 126 \mathrm{~W} 5 a$. The vertical bars show the $95 \%$ probability limits.

Fig. 3. Reversion frequency, as \% reversion to tryptophan independence/survivor, at various exposures to u.v.-radiation, with and without 5 min. post-treatment with white light; Saccharomyces cerevisiae diploid strain J20-10 $126 \mathrm{~W} 5 \mathrm{a}$. The vertical bars show the $95 \%$ probability limits.

Table 1 illustrates the effect of u.v.-irradiation on the parent haploid strains $126 \mathrm{~W} 5 a$ and $J 20-10$. These results indicate that in strain $126 \mathrm{~W} 5 a$ no increase in reversion frequency was measurable. In strain $J 20-10$ reversion to adenine independence was increased from 0 to $0.0042 \pm 0.001 \%$ by 30 sec. exposure to u.v. radiation. Thus the increase in reversion to adenine independence in the diploid strain $J 20-10 \times 125 W 5 a$ could not be accounted for on the basis of a sum of the frequencies of mutation to adenine independence at the $a d_{2}$ loci of the component strains. 
The effect of post-treatment with white light for $5 \mathrm{~min}$. on the number of cells revertant to tryptophan independence is shown in Fig. 3. White light produced a decrease in the number of revertant colonies at the various doses of u.v.-radiation (from approximately 0.02 to 0.01 revertants \% survivors at 60 sec. u.v.-irradiation.

Comparison of Figs. 2 and 3 shows the close similarity between the effect of posttreatment with white light on the reversion to adenine independence and to tryptophan independence. In the reversion to adenine independence the process is that of gene conversion; reversion to tryptophan independence is by mutation.

Table 1. Survival and reversion to adenine independence in Saccharomyces cerevisiae haploid strains $J 20-10$ and $126 \mathrm{~W} 5 a$.

\begin{tabular}{|c|c|c|c|}
\hline Strain & $\begin{array}{l}\text { Ultraviolet } \\
\text { irradiation } \\
\text { (sec.) }\end{array}$ & $\begin{array}{c}\text { Survival } \\
(\%)\end{array}$ & $\begin{array}{c}\text { Revertants/100 } \\
\text { survivors }\end{array}$ \\
\hline $126 \mathrm{~W} 5 a$ & $\begin{array}{r}0 \\
15 \\
30 \\
45\end{array}$ & $\begin{array}{l}100 \\
32 \cdot 7 \pm 4 \cdot 0 \\
16 \cdot 6 \pm 0 \cdot 35 \\
0 \cdot 63 \pm 0 \cdot 097\end{array}$ & $\begin{array}{l}\mathbf{0} \\
\mathbf{0} \\
\mathbf{0} \\
\mathbf{0}\end{array}$ \\
\hline J20-10 & $\begin{array}{r}0 \\
15 \\
30 \\
45 \\
60\end{array}$ & $\begin{array}{l}100 \\
50 \cdot 5 \pm 11 \cdot 8 \\
9 \cdot 06 \pm 1 \cdot 02 \\
2 \cdot 49 \pm 0 \cdot 19 \\
0 \cdot 23 \pm 0 \cdot 049\end{array}$ & $\begin{array}{c}0 \\
0.00146 \pm 0.0002 \\
0.0042 \pm 0.001 \\
0 \\
0\end{array}$ \\
\hline
\end{tabular}

Table 2. The frequency of recessive homozygosis in Saccharomyces cerevisiae diploid strain J 20-10 $\times 126$ W5a occurring after u.v.-irradiation, with and without post-treatment with white light

\begin{tabular}{|c|c|c|c|c|c|}
\hline \multirow{2}{*}{$\begin{array}{l}\text { Ultraviolet } \\
\text { irradiation } \\
\text { (sec.) }\end{array}$} & \multirow{2}{*}{$\begin{array}{c}\text { Colonies } \\
\text { tested } \\
\text { (no.) }\end{array}$} & \multicolumn{4}{|c|}{$\begin{array}{cc}\text { U.v.-irradiation only. } & \text { U.v.-irradiation +5 } \\
\text { white light } \\
\text { Homozygotes } & \text { Homozygotes }\end{array}$} \\
\hline & & (no.) & $(\%)$ & (no.) & $(\%)$ \\
\hline \multicolumn{6}{|c|}{ Homozygosis for $s e_{1}$, and $h i_{8}$, summed } \\
\hline o & 250 & 0 & o & o & $\mathbf{0}$ \\
\hline 15 & 250 & 2 & 0.8 & 1 & 0.4 \\
\hline 30 & 250 & 8 & $3 \cdot 2$ & $\mathbf{3}$ & $1 \cdot 2$ \\
\hline 45 & 250 & 18 & $7 \cdot 2$ & 27 & $10 \cdot 8$ \\
\hline 60 & 250 & $\mathbf{3 1}$ & $12 \cdot 4$ & 39 & $15 \cdot 6$ \\
\hline \multicolumn{6}{|c|}{ Homozygosis for all markers, summed $\left(h i_{8}+s e_{1}+m e_{2}\right)$} \\
\hline $\mathbf{0}$ & 250 & 1 & 0.4 & 1 & 0.4 \\
\hline 15 & 250 & $\mathbf{3}$ & $1 \cdot 2$ & 4 & 1.6 \\
\hline 30 & $\mathbf{2 5 0}$ & 18 & $7 \cdot 2$ & 13 & 5.2 \\
\hline 45 & 250 & 27 & $10 \cdot 8$ & 42 & $16 \cdot 8$ \\
\hline 60 & 250 & 62 & $24 \cdot 8$ & 75 & $30 \cdot 0$ \\
\hline
\end{tabular}

Table 2 shows the occurrence of homozygosity at the $s e_{1}$ and $h i_{8}$ loci on chromosome XII and the $m e_{2}$ locus on another chromosome. The results from all three markers have been summed. There were no significant differences between the results for each marker. These results show that increases in $u . v .-$ irradiation produce an increase in homozygosity by reciprocal recombination (from 0 at 0 sec. u.v.iradiation to $24.8 \%$ of survivors at $60 \mathrm{sec}$.). Post-treatment with white light had no significant effect on reciprocal recombination: after u.v.-irradiation for 60 sec. 
there were $24.8 \%$ homozygotes without white light post-treatment and $30.0 \%$ of homozygotes with post-treatment.

The effect of a constant period of u.v.-irradiation followed by various periods of white light post-treatment on haploid and diploid strains is shown by Figs. 4 and 5 . An increase in the duration of white-light treatment from 0 to $40 \mathrm{~min}$. produced an increase in the number of surviving colonies. In the case of diploid strain $98 / 2 d \times$ $111 / 1 d$, survival increased from $3 \cdot 76 \pm 0.57 \%$ at 0 min. to $23.8 \pm 2.01 \%$ at $40 \mathrm{~min}$. post treatment. In haploid strain $W / 1 / 1 a$ survival increased from $0 \cdot 475 \pm 0.092 \%$

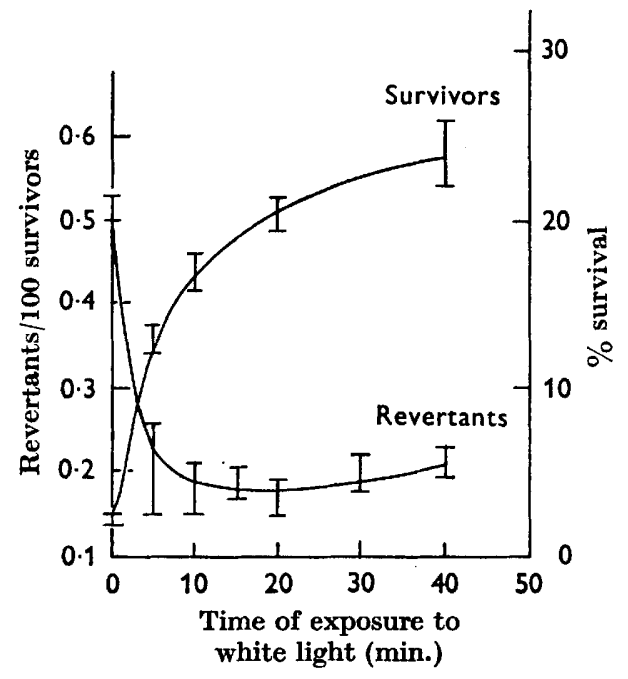

Fig. 4

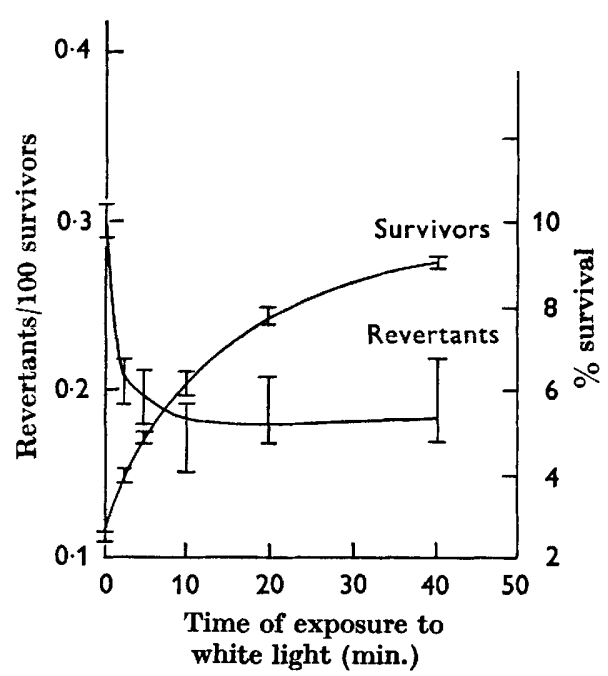

Fig. 5

Fig. 4. Survival and reversion to adenine independence after $60 \mathrm{sec}$. exposure to u.v.radiation, with post-treatment by exposure to white light; Saccharomyces cerevisiae diploid $98 / 2 d \times 111 / 1 d$. The vertical bars show the $95 \%$ probability limits.

Fig. 5. Survival and reversion to adenine independence at $60 \mathrm{sec}$. exposure to u.v.radiation with post-treatment by exposure to white light; $S$. cerevisiae haploid W71/1a. The vertical bars show the $95 \%$ probability limits.

at 0 min. to $6 \cdot 93 \pm 0 \cdot 737 \%$ at $40 \mathrm{~min}$. post-treatment with white light. Reversion frequency can be seen from Figs. 4 and 5 to be decreased aft er $5 \mathrm{~min}$. white light post-treatment from $0.5 \pm 0.025 \%$ to $0.2 \pm 0.1 \%$ in $98 / 2 d \times 111 / 1 d$ and from $0.3 \pm$ $0.01 \%$ to $0.2 \pm 0.02 \%$ in $W 71 / 1 a$. Increases in the duration of light treatment above $5 \mathrm{~min}$. did not further decrease the \% of revertants amongst the surviving colonies.

\section{DISCUSSION}

The frequencies of reciprocal recombination, gene conversion to adenine independence and mutation to tryptophan and adenine independence were all increased by ultraviolet-irradiation. Both gene conversion to adenine independence and mutation to tryptophan or to adenine independence were decreased by post-treatment with white light. This decrease in reversion to prototrophy was accompanied by an increase in survival. This contrasts with the absence of any effect of posttreatment on reciprocal recombination, where the same frequency of recombinants 
was obtained with and without post-treatment with white light. This difference in response between reciprocal recombination and gene conversion was also observed by Pittman (1961) in a diploid yeast heterozygous for adenine requirement ( $A D / a d)$ and heteroallelic for the gene controlling melezitose fermentation (MZ). Fogel \& Hurst (1963) concluded from their results that reciprocal recombination and gene conversion were interdependent; but the present results indicated that the processes are distinguishable by their response to photoreactivation by white light. There are three possible explanations. One is that there is some reversible damage by u.v.-irradiation which is responsible for $90 \%$ of killing, $50 \%$ of gene conversion and mutation events and for no reciprocal recombination. Reciprocal recombination and the remaining $50 \%$ of gene conversion and mutations are due to irreversible u.v.-irradiation damage. The second possibility is that photo-reactivation does not directly affect any of the processes involved in the changing genotype of the yeast cultures, but only survival. The results might be explained by assuming that u.v.irradiation leaves a population of organisms with three components-alive, dead and those moribund but capable of revival by white light. At 60 sec. u.v.-irradiation the fraction capable of revival is about four times the size of the living fraction, but may contain a lower proportion of gene conversions or mutations. As organisms are recovered by photoreactivation, the proportion of revertants among all survivors would decrease. Reciprocal recombination, by contrast, may be assumed to be induced by u.v.-irradiation in a similar proportion of all fractions of the treated population, and therefore white-light reactivation will have no effect on the proportion of homozygous recessives recovered as the degree of survival increases.

The third possibility is that gene conversion and mutation require post-irradiation dark incubation for maximum expression, whereas reciprocal recombination does not. Witkin $(1956,1964)$ reported such an effect in the yield of back-mutations after post-irradiation treatment of bacteria. After 5 min. white light post-treatment of Saccharomyces cerevisiae strains $98 / 2 d \times 111 / 1 d$ and $W 71 / 1 a$, a constant value of revertants/survivor resulted with further increases in light treatment, even though the degree of survival continued to increase. This suggests that u.v.-irradiation induces a fixed frequency of revertants at a given dose, which we may call $(a+b)$, where $a$ is the frequency present after 5 min. post-treatment with white light and $b$ is that frequency which requires dark incubation. The frequency $(a+b)$ will be distributed between survivors and non-survivors in the same ratio of $a / b$. After 5 min. post-treatment with white light, $b$ revertants are lost and do not appear amongst the survivors. Further increases in the duration of white light treatment increases the number of survivors with a subsequent recovery of $a$ revertants among them. Thus increases in survival with white light post-treatment greater than $5 \mathrm{~min}$. will produce a constant percentage of revertants, since survivors are being recovered from the reversibly-damaged fraction of the sample which has $a$ revertant cells.

These results show a remarkable similarity in the response of the processes of gene conversion and of mutation to u.v.-irradiation and photoreactivation. Gene conversion is usually thought of as a process of recombination and therefore distinct from mutation. It will be interesting to determine whether or not there is any basic similarity in the two processes. 
One of us (J.M.P.) is indebted to the Department of Scientific and Industrial Research for a Research Studentship, during the tenure of which this work was done.

\section{REFERENCES}

Carbondale Yeast Genetics Conference (1963). Microbial Genet. Bull. 19, Suppl.

Cox, B. S. (1963). Mitotic recombination in yeast. Proc. 11th int. Congr. Genetics, 1, 15. Cox, B. S. \& Bevan, E. A. (1962). Aneuploidy in Yeast. New Phytol. 61, 342.

DoUDNEY, C. O. \& HAas, F. L. (1958). Modification of ultraviolet-induced mutation frequency and survival in bacteria by post-irradiation treatment. Proc. nat. Acad. Sci., Wash. 44, 390.

Fogel, S. \& Hurst, D. D. (1963). Coincidence relations between gene conversion and mitotic recombination in Saccharomyces. Genetics, 48, 321.

Holliday, R. (1964). A mechanism for gene conversion in fungi. Genet. Res. 5, 282.

James, A. P. \& Lee-Whiring, A. (1955). Radiation induced genetic segregations in vegetative cells of diploid yeast. Genetics, 40,826 .

KaKAR, S. N. (1963). Allelic recombination and its relation to recombination of outside markers in yeast. Genetics, $48,957$.

Pitrman, D. D. (1961). Photoreactivation of ultraviolet-induced reciprocal and nonreciprocal recombination. Bact. Proc. 97.

Roman, H. (1956a). Studies of gene mutation in Saccharomyces. Cold Spr. Harb. Symp. quant. Biol. 21, 175.

Roman, H. (1956b). A system selective for mutations affecting the synthesis of adenine in yeast. C.r. Trav. Lab. Carslberg., Sér. physiol. 26, 299.

Roman, H. (1958). Sur les récombinations nonréciproques chez Saccharomyces cerevisiae et sur les problêmes posés par ces phénomênes. Annls Génét. 1, 11.

Roman, H. (1963). Gene conversion in fungi. In Methodology in Basic Genetics. Ed. by W. J. Burdette, p. 209. San Francisco: Holden-Day Inc.

RomaN, H. \& JACOB, F. (1958). A comparison of spontaneous and ultra-violet induced allelic recombination with reference to the recombination of outside markers. Cold Spr. Harb. Symp. quant. Biol. 23, 155.

WrTkın, E. M. (1956). Time, temperature and protein synthesis: a study of ultravioletinduced mutation in bacteria. Cold. Spr. Harb. Symp. quant. Biol. 21, 123.

Wrtkin, E. M. (1964). Photoreversal and 'dark repair' of mutations to prototrophy induced by ultraviolet light in photoreactivable and non-photoreactivable strains of Escherichia coli. Mutation Res. 1, 22-36. 